\title{
Using Schema Teaching Mode for Students' Cultural Capability through Learning Culture-Type English Courses in Class
}

\author{
Zi LIU*, Qiong MA, and Xiao-Hong DONG \\ School of Foreign Languages, Xi'an Jiaotong University, Xi'an 710049, China \\ ${ }^{*}$ Corresponding author: cjiang@mail.xjtu.edu.cn
}

\begin{abstract}
Keywords: Schema Theory, Social Communication Schemas, Social Science, Culture, Cultural Capability, Critical Thinking.
\end{abstract}

\begin{abstract}
Communicating and thinking capabilities in cross-cultural contexts are playing an important role in future standardized human education judgments under the background of globalization. On the basis of foreign languages teaching activities, we not only train students' capabilities of mastering languages including English, but also enhance their cultural views so as to out-reach the goal of outputting more high-educated people. In this paper, accordingly, we present a kind of social-communication-schema-based teaching mode that increases students' cultural capabilities through culture-type English courses learning in class. Schemas such as fact-and-concept schema, context schema, strategic schema and interactive activities among them are mainly used for constructing a teaching-and-study ecological system in assist of the students training.
\end{abstract}

\section{Importance of Cultural Capability Training in University English}

As the new trend of globalization affects human work and life, communication between people from different countries becomes frequent [1]. Effective inter-cultural communication under the background of nationality, races, religion and life style diversities becomes more usual than ever. As such, modern undergraduate students should not only present skills over systematic thinking and data analysis, but mastery of foreign language for inter-cultural abilities and thinking through frequent international communication, which is also one of the important measures for future personnel standards. Therefore, under the background of globalization, undergraduates should present globalized cultural views and qualities. Only through correct understanding of cross-cultural interaction can people accurately convey and accept information from under cross-cultural backgrounds, which highlights the importance of English and culture training.

\section{Current Situation of Undergraduate Cultural Capacity Training}

University English is presented as one of the mandatory courses in high-level education. Traditional English education aims at the enhancement in basic aspect of English skill including listening, speaking, reading and writing. However, while communication is among the most important functionality of language which is strongly dependent to culture itself, lack of cultural knowledge makes it difficult for the true mastery of English language. As such, even with a degree of English language training, non-English-major students find it difficult for inter-cultural understanding and communication, let alone cultural difference between countries.

While globalization levels the meaning of University English to cultural degree, cross-cultural capacity training should be presented throughout University English education. Therefore, a trending of second year inter-cultural and western English selective courses among non-English major students takes place in university. Those courses, which aim at western culture background and events throughout history, politics, economy, etc, have helped with a cultural understanding of language for undergraduate students and a more efficient usage of English language in hope to reduce the understanding and communicating difficulties caused by cultural difference. 


\section{Schema-based Education Standard in Cultural-type English Course}

\section{Schema Theory}

The development of Schema Theory can be originally traced back to 19-th centaury, by German philosopher Kaut, who views the idea of scheme as a specific form of "productive imagination". The famous Swiss psychologist Jean Piaget verified the role of Schema in children's development during 1920s. In 1930s, British experimental psychologist Bartlett pointed out that Schema is a way of understanding the world for human. Schema helps with memorization and has a variety of forms [2]. Modern Scheme Theory was born after the rise of cognitive psychology in the middle of last 70s. It is said that schematic skills are acquired through direct or indirect experience of environment over a period. As the concept of schema develops, Scheme Theory starts to guide people throughout information processing. Concept of schema helps with a better understanding of complex social cognitive phenomenon. Ever since last 90s, people start to apply scheme theory in the study of cross-cultural communication [3]. Compared to other theories, schema-based theory processes both description and explanation aspects and can be easily applied in real time.

\section{What is Schema?}

Schema is defined as the structure of cognition or knowledge that exists throughout memory. Schema is the abstract understanding of many events in human life and it summaries the important characteristics of those events. Schema is stored within human brains and is acquired through experience. It is the structural summarization of events that repeat with common characteristics without details.

\section{Social Interactive Schema and Cognitive Structure}

As the cognitive structure of human brain, schema has many forms. Social interacting schema comes to place when human processes the face-to-face information during social events. It is commonly divided including fact-and-concept schemas, person schemas, self-schemas, role schemas, context schemas, procedural schemas, strategic schemas, emotion schemas and etc.

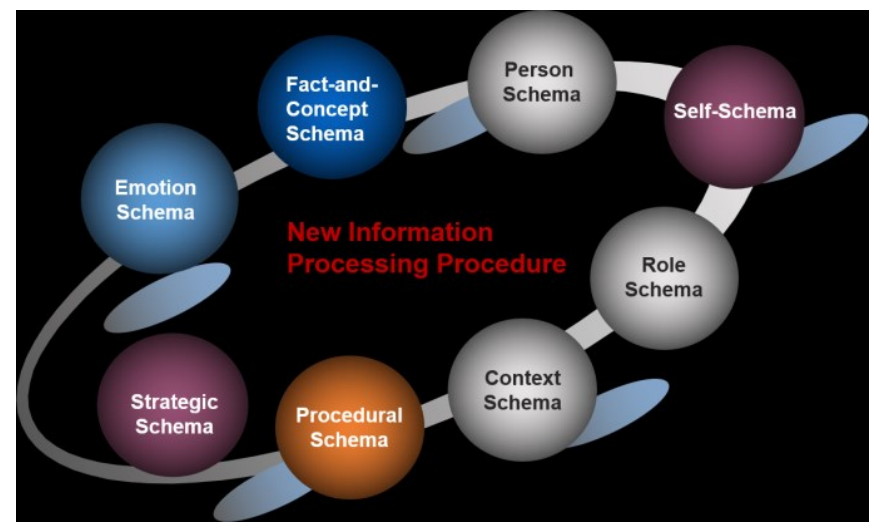

Figure. 1 Category of Schemas and Their Connections

As Fig. 1 presents, different kinds of schemas are connected and interactive with each other. First of all, under special circumstance, human will try to recognize a concrete event, which is required as the procedure of searching through context schemas. Then, after the discovery of a context schema that is similar to current event, a desired goal will be proposed. Further strategic schema will come up to place after achieving the desired goal, which is strongly iterative between context schema and other schemas including self-schema and role schema. When a strategic schema is selected, procedural schema will come along providing a structural guidance of human actions in steps. And in the course of taking actions, human will further judge current instance, select corresponding context schema, and therefore take actions on the basis of a more similar schema for a more concrete event. 
However, the situation described above is more ideal. In real time situation, human tends to fix and establish new schema in the process since lack of specific schema and improper behavior are common in failure of goals. In general, schema has a significant effect over human social behavior. It not only influences the way of selecting, extracting and processing information, but personal behavior as well.

The procedure described above also reveals the cognitive process of schema in social interaction. The schema cognition of social interaction is defined as the structured abstractions replacing the missing details in social interaction, when a schema is formed in human brain. For example, a student can abstract out a tree schema out of countless observation and education activities of specific tree structure, and choose it as the interpretation of relevant concepts. Schema cognition in social interaction is often carried out unconsciously, which influences the specific behavior given specific situation of information processing. Another example is that, students under the training of geometric object classification tend to have a faster recognition of images than those without training.

Under normal circumstance, experience based social schema cognition tends to help with process of large amounts of information. Therefore, when there is a gap in cognition, cognition schema can help to fill in information losses and produce reasonable expectation, which helps to avoid adverse consequences. However, cognition schema can also lead to subjective, one-headed and stubborn view, which impedes the full and accurate reception of information. In general, once cognition schema is formed, when entering a familiar environment, it is more likely that human tends to react or think based on heuristic knowledge in memory.

\section{Cultural Connotation}

There are many definitions for culture. In the innate cognition of human being, culture is typically regarded as a legacy of a nation and the soul of a country. There are also people defining culture as the summarization of art, civilization, music, architecture, history, religion and tradition. Other definitions tend to relate culture to customs and special behavior of population. A sociological definition of culture as the way of life of a group of people, developed over time and passed down from generation to generation [4]. This definition includes every aspect of human life and interaction. Everyday human activities tend to be an extent of one cultural aspect. As Fig. 2 shows, in fact, music, art, architecture, history, religion and traditions are all carriers of culture and the medium of human understanding and feeling of culture.

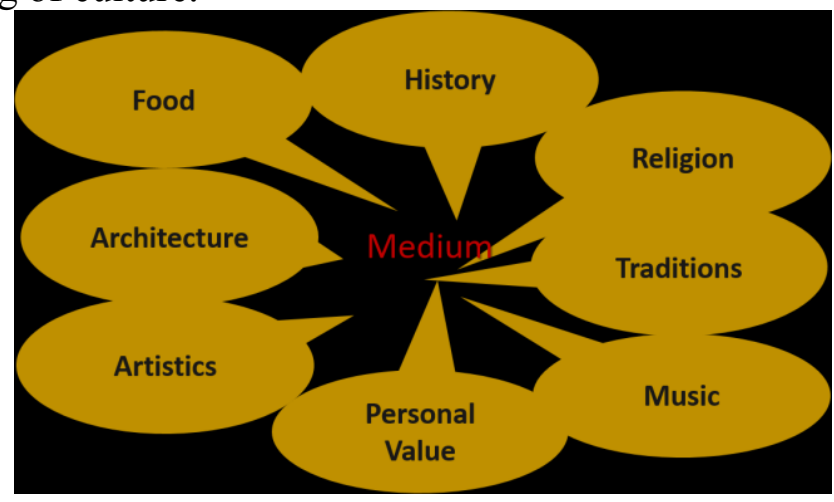

Figure. 2 Medium of Culture

\section{Social Cognition Schema for Cultural Capabilities by Cultural-type English Courses}

Given the situation that social cognition schema tends to help with the explanation of complex social cognition phenomenon, and it can reflect the culture factors of interactive teaching procedure. Therefore, this article presents the result of applying the concept of cognition schema into the teaching of English Cultural classes, which helps to cultivate the cultural accomplishment of University students.

There are many types of social cognition schemas. In the procedure of English culture teaching, this article selects fact-and-concept schemas as the basic knowledge schema for teaching key points and 
corresponding cultural connotations. Context schema is applied as the description of student-teacher interaction and corresponding actions. Strategic schema is used to express the teacher-student behavior during teaching interaction scene and combines teaching key points and cultural aspect into knowledge that students learn. Therefore, teachers can help students with external stimuli (such as details during teaching interactive) with a proposed acquisition of the overall concept (such as teaching knowledge points and the corresponding cultural connotation) phase, filter out unnecessary information, and create the future teaching knowledge points and the corresponding cultural connotation expectation by the use of schemas.

\section{Selection of Teaching Materials: A Rational Statement of Facts and Conceptual Schema}

First of all, selection of teaching materials should be consistent with the objectives of course teaching, that is, teaching should serve the training objectives of the course, rather than the reverse. Teaching materials should always come first, and teaching objectives should be formed accordingly. It is widely known that social science is the study of natural, social development of human social behaviors. Selection of a Chinese-English textbook should cut in through the discussion of sociological perspective, which can help with more general and scientific knowledge of generalized schema for cultural facts during the teaching of students. Providing with materials including vocabulary, reading, writing, listening, discussion and network activities can help with a better establishment of cultural communication platform and general schema of cultural concept for students. Textbooks which serve as a theoretical system, if able to focus on videos, network information, books and movies related to culture, media, trending events, will play an effective role in the objective cumulative achievements.

\section{Design of Teaching Scheme and Content: Settings of Situation Mode}

Besides the selection of good teaching materials, scientific design of teaching plans and proper in-class contents are also important. However, it is impossible to demonstrate every angle of a nation's cultural life in a single course. Therefore, a method focusing on mainstream values and related examples, promoting social development and progressing and guidance over the behavior and lifestyle of a particular population is needed. Further discussion over influence of population should be taken into consideration for the study of mainstream value establishment. In fact, everyday human activities tend to be reflected from an aspect of culture, which includes the trajectory of historical development, the heritage of tradition and religion, the political and economic structure of the country, the educational system and ideas, etc. Through the scientific establishment of context schema over different cultures, in-class study can help with a more proper social communication and understanding, which also help to form a solid cultural literacy.

It should be pointed out that, during the teaching of University English classes, context schema carries the task of culture transferring through in-class teacher-student iteration. Context schema is also dependent to the design of social interaction scenario in teaching plan, which is supported not only by indirect experience over a large number of cultural events, but teacher's oversight beyond nations. Media materials will also help with a better formulation of context schema. In addition, invitation of foreign teachers can further compensate teachings for simulation lost.

\section{Guidance of In-class Iteration: Application of Strategic Schema}

The goal of in-class iteration is to help with the establishment of strategic schema which develops critical thinking and other potentials of students and therefore strengthens the understanding of case driven and problem-solving strategies. Types of in-class activities include reading and understanding of teaching materials, relevant extension of video/book/Internet materials, in-class discussion based on reading activities, group reports regarding discussion and etc. It should be noted that, the settings of events and the abstraction of questions should have the properties including evidence-base, optional-solution and open-minded creation, which further encourage more questions and thinking that help with students' own cultural understanding. When similar context schema is found for current event, a goal will be presented by current schema. When the goal is confirmed, a further 
strategic of achieving this goal will be presented as well. Strategic schema is relevant not only to context schema, but to other schemas including personal schema, self-schema as well.

\section{Importance of Schema-based Teaching Understanding}

As Fig. 3 shows, schemas presented above formulate a schematic cognition of teaching strategy in University English class. This schema based cognitive approach helps students to deal with a large amount of information quickly and economically, which further helps with students' own formulation of schemas. In general, scientific methods of establishing social cognition schema have a significant impact on future social cross-cultural iterations for students. Not only does social cognition schema influences students' selecting, extracting and processing of information, it also influences individual behavior orientation, which is beneficial to complex social phenomenon explanation in English. It guides University students to better process new information, establish future expectation of information, and form a cross-cultural critical thinking. In-class activities which focus on dialectical critical thinking practicing not only cultivate students' cultural quality, but develop their creativities as well.

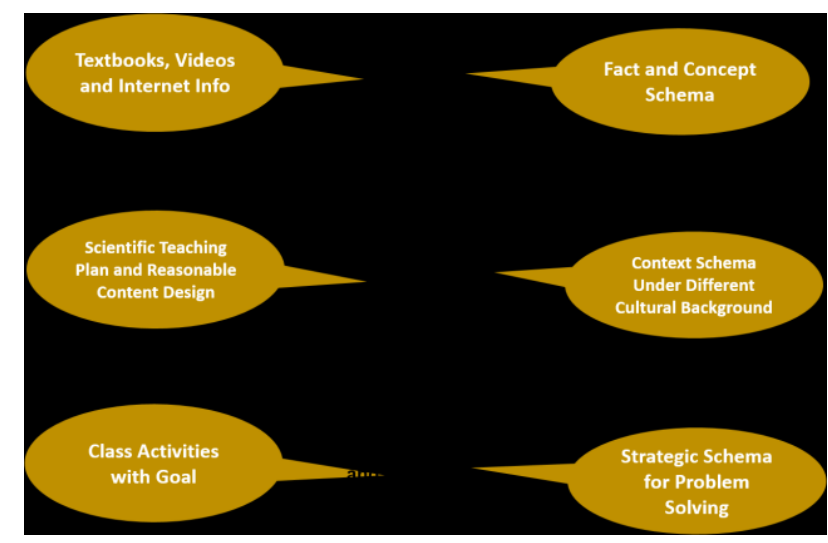

Figure. 3 Relationship Between Schemas and Teaching Design

\section{Concluding Remarks}

In summary, under the circumstance of a schema-based course design, scientific ways of teaching materials selection, comprehensive design of teaching schedules and contents and proper organization of in-class activities not only help to enhance the real-time English applications of students, but achieve the goal of cross-culture communication. On the basis of globalization, how to properly develop University students' artistic appreciation and intercultural communication ability is beyond importance. Understanding of inter-cultural background over different nations and races is strongly relevant to an efficient cooperation in worldwide companies and organizations. Inter-cultural communications come out on top when information generated by one person of specific culture background is absorbed by another of a different culture background. The social cognition schema based teaching method this article presents not only help with a better achievement of teaching goal, but an exploration of cross-culture cultivation which comes to life by combining concept schema, context schema and strategic schema. Due to the limitation of article, a further discussion over quantification of schema-based University English teaching will be presented in future.

\section{References}

[1] Z Liu. A qualitative analysis on cross-culture communication and its context perception in collaborative work processes, Int. Journal of Internet Manufacturing and Services, 2010, 2(2): 156-165.

[2] KJ Duff. Social Psychology, 2013. 
[3] XL Tang. Schema Theory for Cross-cultural communication, Master Thesis, Qingdao University of Technology, 2010, 63pp

[4] E Hunt and D Hunter. Introduction to Social Science, 2012. 